\title{
Teaching and learning the nature of technical artifacts
}

\author{
Ineke Frederik • Wim Sonneveld • Marc J. de Vries
}

Published online: 31 March 2010

(C) The Author(s) 2010. This article is published with open access at Springerlink.com

\begin{abstract}
Artifacts are probably our most obvious everyday encounter with technology. Therefore, a good understanding of the nature of technical artifacts is a relevant part of technological literacy. In this article we draw from the philosophy of technology to develop a conceptualization of technical artifacts that can be used for educational purposes. Furthermore we report a small exploratory empirical study to see to what extent teachers' intuitive ideas about artifacts match with the way philosophers write about the nature of artifacts. Finally, we suggest a teaching and learning strategy for improving (student) teachers' concepts of technical artifacts through practical activities.
\end{abstract}

Keywords Philosophy of technology $\cdot$ Technical artifacts · Designing

\section{Introduction}

Technological literacy is often seen as the ultimate aim of teaching and learning about technology. The term has not been well defined, but generally speaking it entails the ability to live in a technological world as a citizen who is not flabbergasted by the magic of technology but is able to control it and make informed decisions about what is good and what is bad use of technology. Besides this type of literacy, another aim of teaching about technology is to enable students to make an informed decision about whether or not to opt for a technological career. In that case the literacy is extended to not only using and judging technology, but also contributing to its further development. The immediate way we meet technology everyday is through the technical artifacts that surround us. We see buildings, cars, traffic lights, chairs, tables, pencils, sheets of paper, computers, fridges and television sets, and so on. Even before we realize that technology is also a body of knowledge, that technology entails designing and producing, that technology is part of our human being (Mitcham 1984), we see these artifacts. What could be a more natural starting

I. Frederik $(\varangle) \cdot$ W. Sonneveld · M. J. de Vries

Science Education and Communication, Delft University of Technology,

Delft, The Netherlands

e-mail: j.e.frederik@tudelft.nl 
point for teaching and learning about technology than studying the nature of these artifacts?

But how do we teach about artifacts in a way that makes a serious contribution to technological literacy? At first sight it seems to make sense to try to make pupils acquainted with a variety of artifacts, the selection of which will depend on the role they play in everyday life. In such an approach pupils will learn all sorts of details about different artifacts that they meet in daily life. There is, though, a problem with that approach. The amount of artifacts pupils encounter everyday is almost endless. Besides that, the educational effort made to make them understand those artifacts would soon be outdated, as new artifacts constantly enter our lives. Without an understanding that exceeds the individual artifact, each bit of knowledge about a particular artifact soon becomes less relevant because new artifacts have taken the place of old ones. The way artifacts are presented in education should be such that pupils learn to recognize characteristics of the artifact that are not specific for one specific artifact, but that relate to the very nature of all technical artifacts. In other words: conceptualizing artifacts should be an objective in our teaching about technology. Pupils ought to learn about the nature of technical artifacts rather than become familiar with the details of individual artifacts.

To be able to develop learning situations, teachers themselves must also have knowledge of the nature of technical artifacts. It is surprising how little we know about the way teachers think about the nature of technical artifacts. The same holds for our knowledge about what pupils think about artifacts. What we know is that they play an important role in their concept of technology in general. Artifacts are the most prominent feature in pupils' (intuitive) concepts of technology (Bame et al. 1993). But we hardly know how they think about artifacts. Do they recognize that artifacts have properties in common and that this is why we call them artifacts? There is a need for educational research here. But in order to make sense of the outcomes of such research, it is necessary to have a point of reference for what the nature of technical artifacts could be. It makes sense to seek this point of reference in the philosophy of technology, because this is the academic discipline that specializes in seeking out the nature of technology, including technical artifacts. This discipline can serve as a rich source of information about the nature of technical artifacts, as we will see.

In this article we will first explore what the philosophy of technology has to offer in terms of insights about the nature of technical artifacts. Then we will report a small empirical study among teachers in which we have investigated the way they conceptualize certain features in the nature of technical artifacts, as we learnt them from the philosophy of technology. Based on our findings we will suggest a teaching strategy to improve teachers' understanding of technical artifacts, which can also be used-in an adapted version-for classroom teaching.

\section{Philosophy of technology on the nature of technical artifacts}

In the early days of philosophy of technology, there was not much interest in technical artifacts. Most philosophers in this domain were more concerned with the relationships between technology and our human being as well as with the way technology impacts our culture (and vice versa). Quite opposite opinions were developed about this. Heidegger and the phenomenologists in his footsteps wrote about technology in a quite negative way: technology has made us look on reality as only something that still needs processing in order to become useful to and, and has almost no intrinsic value. Marxists, to the contrary, had great expectations of technology as the catalyst that would bring the desired 
transformation of society and its classes. This was all on a very general level of analysis. No explicit attention was paid to the nature of technical artifacts as the concrete manifestation of technology (De Vries 2005).

An interest in philosophical reflection on the nature of technical artifacts did not awaken until a more analytical philosophy of technology emerged. This type of philosophy was interested in defining and conceptualizing key aspects involved in the practice of technology, rather than just concentrating on a critical debate about the role of technology in culture and human life. It was in this type of technology that philosophers with also a background in engineering became involved. This background enabled them to study the nature of technology 'from inside' in stead of drawing outsiders' pictures as the earlier philosophers in the Continental tradition (Heidegger, Marx, etc.) had done. One of the institutes that became involved in this new type of philosophy of technology was the Delft University of Technology. The philosophy section at this institute has done a major study in the nature of technical artifacts in a research program titled "The Dual Nature of Artifacts" (Kroes and Meijers 2006). We will now describe the way technical artifacts are conceptualized in this program and explore its relevance for education about technology.

Of course the most obvious way of thinking about artifacts is that they are human-made objects (the literal meaning or the word arte-factus in Latin is something like: made with skill). That makes them different from natural objects, which are not human-made. This, however, tells us more about the history of the object than of its actual meaning in our lives. In some cases we even try to hide this difference, such as in the case of artificial flowers (the more they hide their artificiality, the better). Furthermore, it does not differentiate between technical artifacts and other artifacts such as works of art. To give a proper account of technical artifacts, we need to involve the concept of functions. Technical artifacts are human-made objects that have a certain function, and have been made because of that. Function only also is insufficient to give a full account of technical artifacts, as there are other entities that have functions, but are not technical artifacts. One can think of, e.g., words in a language, or numbers in mathematics. To be a technical artifact, the entity needs to have a function, but also to be a physical object. This combination only can be the basis for a full account of technical artifacts, and this is precisely how the "Dual Nature of Technical Artifacts" program has conceptualized technical artifacts.

Let us take a corkscrew as an example. The corkscrew can be described entirely in terms of its physical make-up. It has a certain weight, a certain color or combination of colors, it has a certain shape, a number of parts, it is made of certain materials with certain chemical, optical, mechanical, electrical, magnetic (etc.) properties. But if one would describe the corkscrew in this manner to someone who does not know what a corkscrew is, (s)he may think of an object that is to be used for all sorts of different purposes (especially if the description does not mention that the corkscrew has something to do with wine bottles). Because of its weight, it could, for instance, be used as a paper weight on a desk. One could question if this is what the designer had in mind, given the fact that the corkscrew's shape and construction seems to be way to complex to make it an efficient paper weight. Dennett (1989) has claimed that when taking a design stance in our reflection on the object, we could derive its intended function by reasoning about what it would be most fit for (and thus implicitly assume that the designer has chosen the physical make-up that would be the best for the intended function). This can be challenged, as Krist Vaesen has shown in his dissertation (Vaesen 2008). Still, Dennett is correct in recognizing that users will try to deduce the function of the artifact from its physical make-up in case this function is unknown to him/her. Coming back to our corkscrew, we could also give a complete description of its function: it can be used to extract corks from whine bottles, and perhaps it 
also has a little device that can be used to cut off the plastic cover that protects the cork. But again, this description is incomplete for someone who does not know what a corkscrew is. (S)he might imagine objects that are totally different from what we know as corkscrews. In fact, (s)he might invent new and perhaps even better corkscrews by doing so. This is very much what designers do: they try to reason from a desired function to a physical make-up that enables the realization of that function.

To summarize: a full account of a technical artifact can only be given by describing both its function and its physical make-up (or in the terms used in the Dual Nature program: by its functional nature and its physical nature, in short: its function and its structure). Both designers and users use reasoning patterns to get from one nature to the other. A good design is one in which an optimal fit exists between the two natures. It is important to note that the functional description is normative, whereas the physical description is nonnormative. The function is what the artifact ought to do. A broken car does not factually bring people from A to B (and is not even able to do so), but still its function is to do that. The function is normative, not descriptive. But the physical structure describes things as they are. The car factually has four wheels, a chassis, etc. There is no normativity in that.

How does learning this contribute to technological literacy? In that it gives a very suitable entry to learning about what technology is all about, namely about developing and using objects that integrate human and social needs and wants, hopes and expectations (reflected in the functional nature of the artifact) and the physical resources that we have available in our environment that we adapt to make that environment fit better with our needs (the physical nature), The dual nature also offers an insight into the heart of each design problem, namely to develop this integration of human needs and wants and the physical resources through which these can be addressed. Design is commonly regarded to be one of the most important and representative activities in technology, and an understanding of design is crucial to technological literacy. The activity that we are about to describe now does not fully cover all that, but it is a first step towards a full understanding of how the nature artifacts informs us about what design and technology are all about.

\section{Teachers and their awareness of the two natures of technical artifacts: an empirical case study}

The empirical study that is reported here concerns a group of teachers who participated in in-service training activities, offered as a part of our science education program at the Delft University of Technology. As our program is situated in a university that specializes in engineering, our science education program has a specific design focus. We exploit design activities in the teaching and learning of science, and besides that we also treat design skills as a legitimate and important part of (future) science teachers' skills. So design activities have both an instrumental role, but also have an intrinsic value. We strive at offering activities for teachers that easily translate into classroom level. The 'mysterious artifacts' activities used in this study are of such a kind (Frederik and Sonneveld 2007). This activity is also part of a workshop designed to give teachers a concise view of what technology is and of the kind of activities engineers perform. We use artifacts of which the function is unknown to make teachers reflect on the physical and functional natures of that artifact and on the relation between these two natures. Thus, we help them get an understanding of the nature of technical artifacts, as described in the previous section. To help them understand these natures, we start with known artifacts, such as a corkscrew. We make them aware that the physical and structural properties of the corkscrew (metal, sharp tip, handle, 
sometimes a lever) have all been chosen by the designer such that the corkscrew can perform a certain function (extracting corks from wine bottles). This requires a careful investigation of possible functions and possible physical features. In the empirical study reported here we have investigated to what extent the teachers had intuitive ideas about the dual nature of technical artifacts.

In our empirical study we have distinguished two groups of experienced science teachers in secondary schools:

- 25 teachers with some experience in teaching technology (the 'experienced' group) and

- 21 teachers without such experience (the 'unexperienced' group).

By 'teaching technology' we mean classroom activities in which the design process is given explicit attention. In our case this was done in the context of science education. We expect that teaching experience has an influence on their ideas about the dual nature of technical artifacts, as the experienced teachers have had more reason to have reflected on this issue. As this study is rather exploratory, we have not chosen an experimental research design in which this suggestion is tested as a hypothesis.

All teachers are experienced teachers, the majority having five and more years of teaching experience, but their experience in teaching about technology varies. Based on their training (in science), most of them can be expected to have at least some basic knowledge about materials and material properties and a certain basic vocabulary for expressing that knowledge. Their vocabulary for expressing functions of the unknown objects can be expected to be based on common sense and everyday experience, similar to other teachers who have had no training in science.

During the workshops we tried to provide teachers with scaffolds to help them teach design skills in their own teaching practice. The activities were meant to be examples of classroom activities for pupils, but must also be interesting for teachers in their own right. We argue that they show what engineers do while designing artefacts that fulfil a specified function: they connect properties of the artefact (the physical nature, or structure, in 'dual nature' terms) with the tasks they are to perform (the functional nature, or function, in 'dual nature' terms). This activity proved to be interesting and inspiring in its own right but at the same time is exemplary of design tasks in general. Another requirement of this kind of scaffold is that it must have a low threshold for bringing it into practice. It is easy to organise and thus usable 'tomorrow' in the teachers' own classroom.

\section{Experimental setting: workshop for teachers}

We used the 'mysterious object exercise' as described in Frederik and Sonneveld 2007.

The discussion leader brings a box with mysterious objects. He chose the items in the box because they intrigued him (Fig. 1) and he did not immediately recognize them or knew their purpose. Some of them are old, antique or otherwise out of date. All kinds of shapes, colors or sizes are present. Some were bought, others collected in flea-markets or with the help of friends. Most artifacts are commercially mass produced and sold, a very few are home-made for a very special purpose. All are given a tag with a number for use in the classroom.

The discussion leader explains about properties ('structure' in 'dual nature' terms) and functions by giving an example: the corkscrew (Fig. 2). Corkscrews have several properties, for instance the pointed tip. That is because a corkscrew should make a hole in a cork, so the screw may be pushed easily into the cork. The corkscrew also has a screwy 


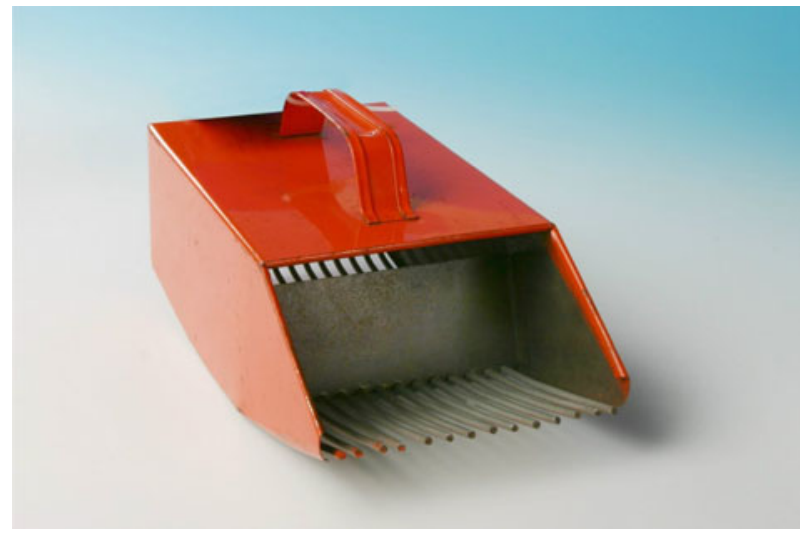

Fig. 1 One of the mysterious objects used in the workshop

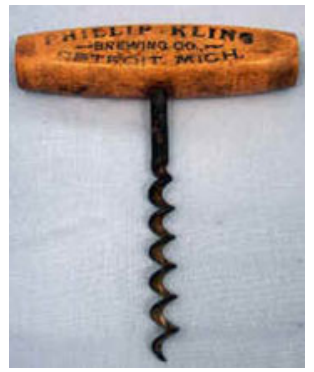

Fig. 2 A corkscrew is used to explain about properties and tasks

shaft. What for? Again, the corkscrew should turn easily into the cork and require some force when pulling. The handle of the corkscrew is wider than the screw itself. Again: why, what is the use? My 'why's' and 'what for's' are at this stage easily answered by the participants. They realize soon that that you have to look carefully at the object and with every property start to ask 'why' and 'what for'. Table 1 appears showing that properties and tasks are related.

Now they may do the exercise themselves with unfamiliar objects (Fig. 3). Each member of the group gets a worksheet. Everyone writes down his/her name, group and the number of the object. They fill the table on the worksheet with as many properties and tasks they can discover. They invent a name for their object and describe with a short sentence its main function.

Finally they must make a commercial of the 'tell-sell' type to advertise their item and explain to their class mates why everyone should buy this particular object. Note that from now on we will use the term 'property' for what was called 'physical nature' or 'structure' in the dual nature approach and 'task' for the functional nature, as these were the terms as we used them in the workshop.

First of all it is striking that almost immediately a lively discussion takes place. Although participants are meant to fill in the worksheets individually before discussing their finding with others, the individual part ends almost before it starts. A pub-like atmosphere exists 
Table 1 Some properties and tasks of the corkscrew

\begin{tabular}{ll}
\hline Property & Task \\
\hline Sharp tip & Make a hole \\
Broad handle & Better grip and turn more easily \\
Screwy shaft & Easy to put into the cork, much resistance when pulling \\
Metal shaft & Strong and sturdy \\
\hline
\end{tabular}
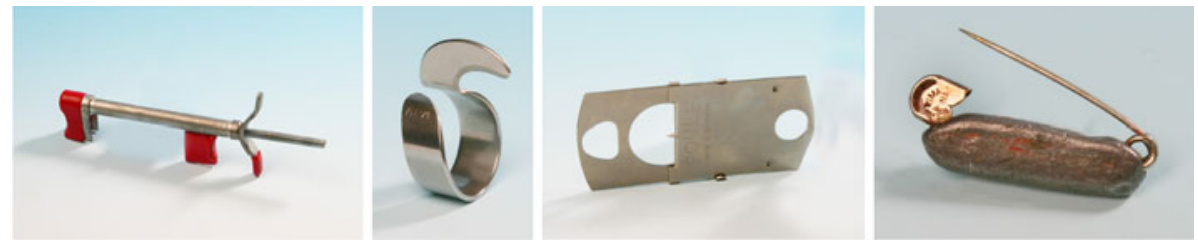

Fig. 3 More examples of mysterious objects

and curiosity reigns. The enthusiasm is almost independent of years of teaching experience or subject taught, as long as the artifacts are mysterious enough for the target group. Talking about technology and using the language associated with technological concepts also contributes - in our opinion at all levels- to the technological literacy of participants.

We found great spontaneity in the worksheets and much eagerness for tasks the teachers had to perform after completing the worksheets. Group discussion and tell-sell presentations clearly had more appeal to the participants than filling in worksheets.

The workshop participants did not critically contemplate what they wrote. This, however, does not mean the data are not usable. The teacher did make a serious effort to write at least their primary ideas. At the same time, we realize that no in-depth conclusions can be drawn from these data. But that was not the intention, given the exploratory nature of this small study. We do consider these worksheets as written evidence of their primary thought processes and considerations and a more or less proper picture of preconceptions of the participants regarding the distinction and correlation between properties and tasks, though not accurate or in-depth. We also believe the instruction given to them was adequate enough to make them well aware of what was expected from them. The activity and the form were very simple and straightforward, so it is not likely that what they wrote was the result of incomplete or unclear instruction.

\section{Findings}

As mentioned above, the teachers did not like to fill in forms. Often we find well filled empty spaces in the worksheet, full of rapidly jotted down observations and associations. Usually there are more items in the property column than in the task column, although different respondents vary a lot in the number of items they jot down. The teachers' negative attitude towards forms can be partially the explanation for this. However, we think a lack of conceptualization may also be at stake here. We wondered therefore:

- what view the respondents had of properties and tasks,

- if they connected properties and tasks properly 
We now look more closely at some of the worksheets and describe them into more detail to get an impression of what can be the answers to these questions.

Respondent 12 has a red, boxlike artefact (Fig. 1). It is used to pick and collect cranberries. In the property column (Fig. 4) he writes: 'handle' (handvat). We consider the shape on top of the artefact indeed as a property, material shaped so it may be easily held by hand. To handle the artefact by holding the handle is more a task than a property. Tasks are usually verbs. In this case, as we have seen in many more cases, the property mentioned is actually a task.

The task this person mentions is in the same row as 'handle' is 'to scoop'. The respondent found the scooping task evident when he looked at the object, but to connect 'handle' automatically with a scooping requires more information about properties of this artefact. From the designers' point of view properties and tasks should be more logically connected.

This respondent also lists more properties than tasks. For instance he mentions in row 5: 'small combs' but does not write down a task that might be connected with this so called property. Other rows however, show more properly connected properties and tasks, for instance row 3: 'metal' for 'sturdiness'.

Respondent 9 considers a horse comb (Fig. 5). His worksheet (Fig. 6) clearly shows which artefact he is describing. But the property column of the blue plastic artefact with a very special shape contains 'handle', 'comb like' i.e., tasks rather than properties. The respondent connects the shape to a task and jumps to conclusions. He respects that one property may have more tasks and vice versa but takes shortcuts. With comb-like artefacts you may comb, rake, but to scrape with it is odd. It is more likely that one scrapes with the flat surface. Yet one may rake with the plastic teeth and scrape a liquid with the rubber part of the artefact. This participant takes more shortcuts that show a mixture of observation and interpretation. He calls 'protection rubber' as a property (left column, third row: 'beschermingsrubber'), which in fact is a mixture of a property ('made of rubber') and a task ('to protect'). For the task related to this 'property', he writes in the right column 'larger surface' ('groter oppervlak'). That is confusing, because surface is a property, not a task. What he may have meant is that by moving the rubber part one can cover a larger surface, but this is not sure. In the second row he mentions 'handle-grip' as a property, but offering grip is more a task of the plastic protrusion.

Respondents 40 (Fig. 7) and 41 (Fig. 8) also had the artefact shown in Fig. 5. They wrote down more details than respondent 12 , which may be due to the fact that they have

\begin{tabular}{|c|c|c|}
\hline & eigenschappen & taken \\
\hline 1 & handrat & on mee $t$ seluppesin \\
\hline 2 & rood & makkelyn tones roud \\
\hline 3 & metaral & han tegen een sarbe \\
\hline 4 & Extra) daninely & \\
\hline 5 & nomnebis. & \\
\hline 6 & siaal. & met vor water \\
\hline
\end{tabular}

Fig. 4 Respondent 12's worksheet 


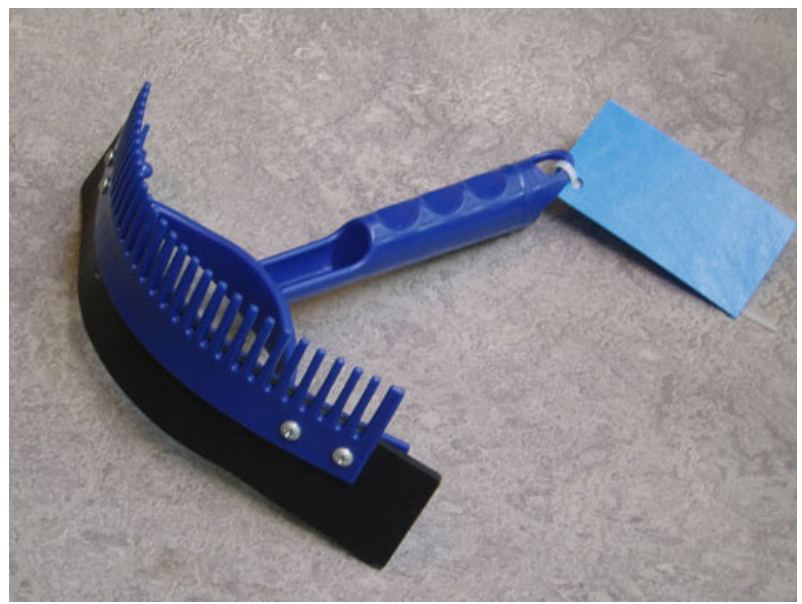

Fig. 5 A horse comb as mysterious object

\begin{tabular}{|l|l|l|}
\cline { 2 - 3 } \multicolumn{1}{c|}{} & \multicolumn{1}{|c|}{ eigenschappen } & \multicolumn{1}{c|}{ taken } \\
\hline 1 & KAM ALHTHG. & SCHRAPGN / HARKEN \\
\hline 2 & HAN D VAT - GRIP. & GRIP. \\
\hline 3 & BESCHERMINGS RUBBER. & GRGTER OPPER VL
\end{tabular}

Fig. 6 Respondent 9's worksheet

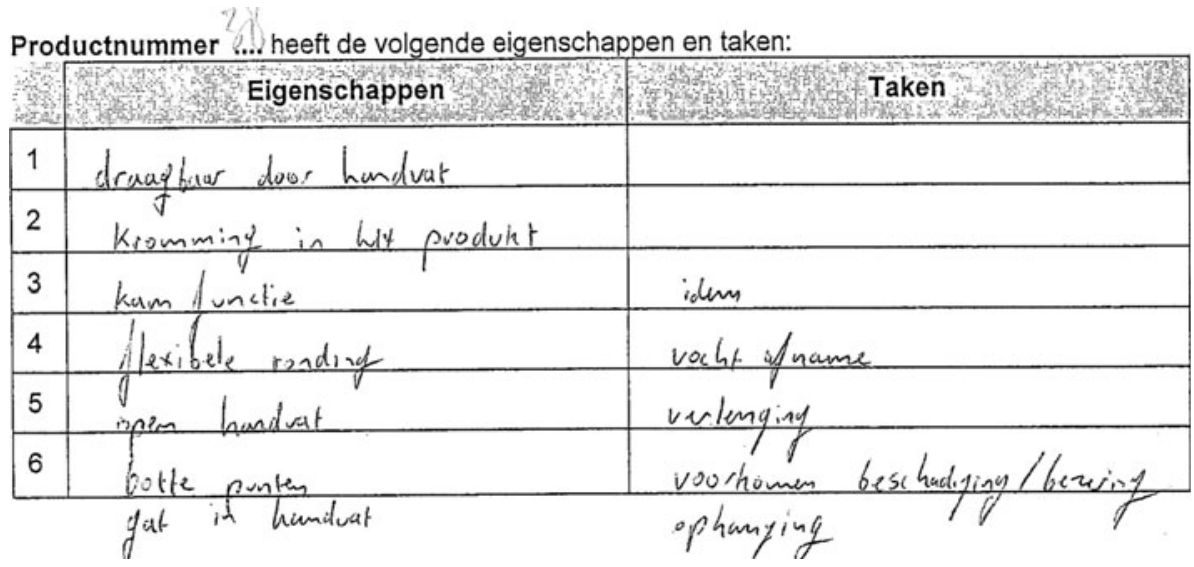

Fig. 7 Respondent 40's worksheet

some experience in teaching technology and/or science. One of them, however, mentions as properties: 'portable' and 'comb function'. These are certainly not properties, but taskrelated issues. Other properties they mention are 'extensible' (verlengbaar), 'suspendable' (ophangbaar), and again these are not properties but a mix of properties and tasks. 


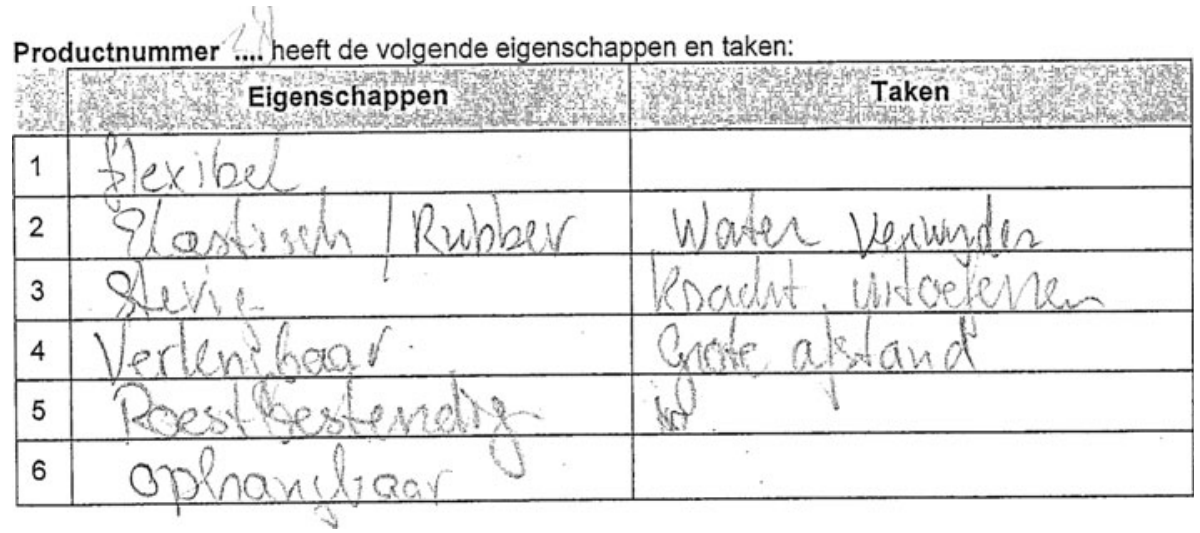

Fig. 8 Respondent 41's worksheet

In summary: the worksheets show that teachers in our target group:

- mention more properties than tasks,

- write tasks in the property column,

- mention properties in the task column (less frequently),

- write concepts in the property column that could be either property or task,

- mismatch concepts in the property column and concepts in the task column,

- seldom recognize that a property fulfills more than one task,

- experienced teachers (i.e., teachers experienced in teaching design skills) generally mention more properties and tasks and match properties and tasks more correctly.

Our target group show an interesting amount of mix-ups, illustrating that in the minds of these teachers, properties and tasks are not clearly differentiated. We believe this is not due to our instructions but to a real lack of understanding. These results show that more effort is needed to clarify the distinction between properties and tasks. A better balanced curriculum is needed both for them and most likely also for their future pupils.

\section{Conclusion and discussion}

The pilot study suggests that both experienced and inexperienced teachers do not fully grasp the concepts related to the dual nature of technical artifacts. We conclude that the knowledge of science teachers and especially teachers inexperienced in teaching about technology regarding the dual nature of technical artifacts needs to be improved. Their problems in discerning functions and properties may improve by activities that are easy to use, have low threshold regarding material and do not require time-consuming preparations. As indeed we noticed in activities following the in-service course: most teachers implemented this activity and adapted it for use in their own practice. It proved to be attractive and challenging for teachers to design their own worksheets. And by doing so they expanded their knowledge of functions and properties.

We conclude that more effort is needed to help teachers teach about one of the most central themes engineering practice: matching artifact properties to tasks. We propose to use the following teaching sequence using three capability tasks. 


\section{Proposed capability tasks}

The first exercise focuses on properties.

We use a number of objects, well known to the target group of the exercise: a stapler, a coin, a key ring with keys, a pair of scissors, a telephone, a credit card, pencil sharpener, pocket calculator etcetera. We select familiar objects consisting of more than one material and a distinctive shape, preferably with movable parts (Fig. 9).

The discussion leader uses subgroups of three or four persons. Before starting the exercise the discussion leader demonstrates the process in front of the group or the class. (S)he mentions explicitly only to mention properties and certainly not to mention their own conclusion about the object in the bag.

Each subgroup then gets a bag containing one object (Fig. 10). One person in the subgroup puts his hands in the bag and feels the object. Only feeling is allowed. (S)he has to mention as many properties as (s)he can think of while feeling the object. They should

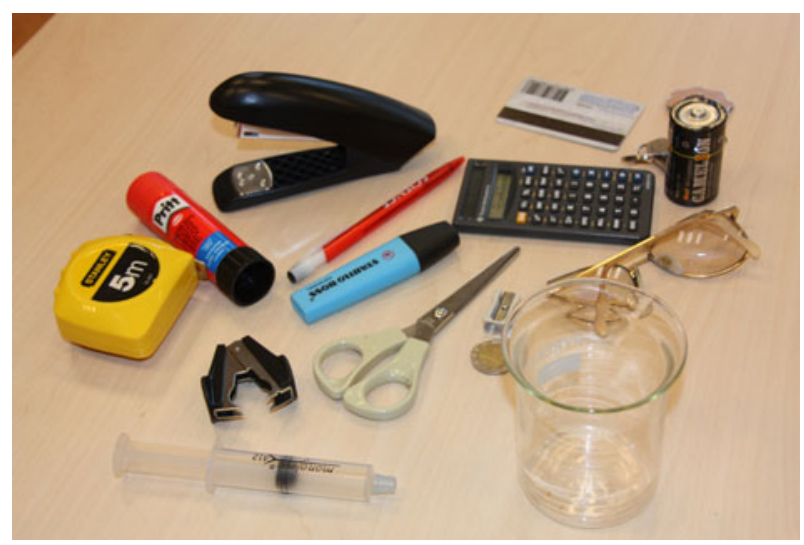

Fig. 9 Well known artifacts

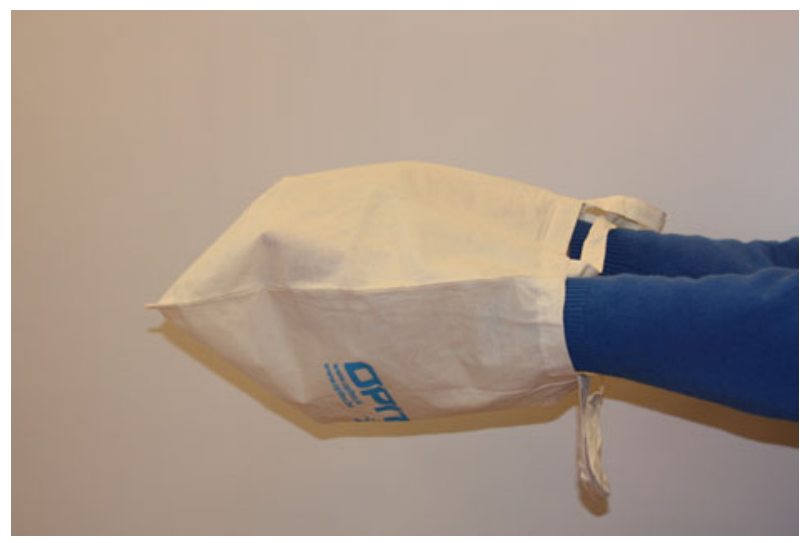

Fig. 10 Bag containing an artifact 
not mention conclusions about possible functions that one might derive from the properties of the object.

In response to the properties mentioned each group member may ask questions, again to specify properties of the object. After a limited time (about $8 \mathrm{~min}$ ) every group member sketches the object and also writes the properties on his sketch. They also list the properties in a table on the worksheet. Subsequently the object is shown and the group members compare their sketches and properties they wrote on the worksheet. They discuss what properties they consider to be relevant. Each group then devises a group table mentioning properties and the tasks connected with each property.

The discussion leader summarizes and illustrates the connection between properties and tasks and also shows that one property may fulfill different tasks and vice versa. This exercise takes about $25 \mathrm{~min}$. It is meant to be short, inspire active participation and discussion while working towards a conclusion needed later on.

The second capability task focuses on tasks and is a brainstorming exercise resulting in a poster presentation. Each group is asked to think of as many instances as possible of situations where a given task is performed. They can think, for instance, of as many possibilities as possible to open and close something. The task, 'to open and close', appears in a central position on a poster. Participants are invited to think laterally and creatively. They may write or draw. This exercise is useful and the way of thinking is necessary when you are trying to design an artifact. In design usually more solutions are correct and thinking of as many possibilities as possible may result in a better, an optimal end-product (Figs. 11, 12).

Inexperienced problem solvers tend to focus on the first solution that enters their minds. This is efficient in many school subjects, but for a proper design process both thinking of alternatives and later making a reasonable, defendable, educated choice between alternatives is important. This thinking in all different directions, associating, using you knowledge and experience we consider as central in teaching about technology.

The posters are shown. The discussion leader points out the variety of associations and to the unique directions some group discussions took. It is important to emphasize again that there are many ways in which to fulfill a task each asking for other properties of the artifact.

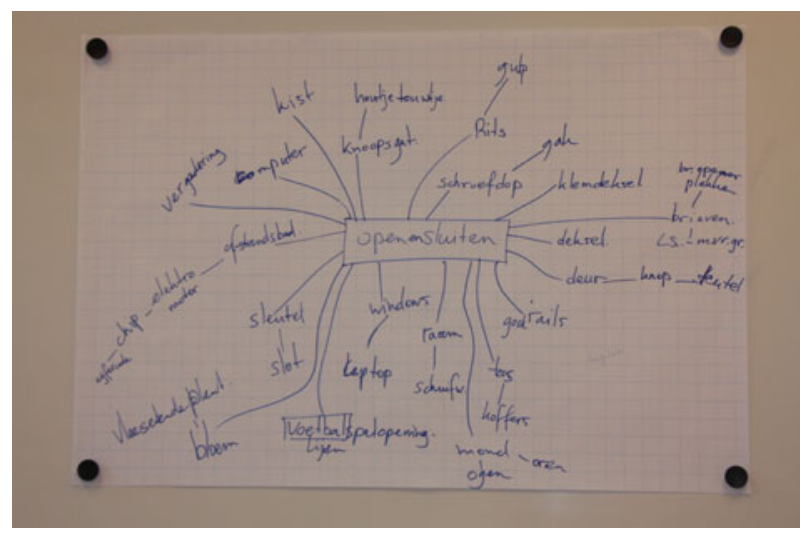

Fig. 11 Possible solutions to a given task 


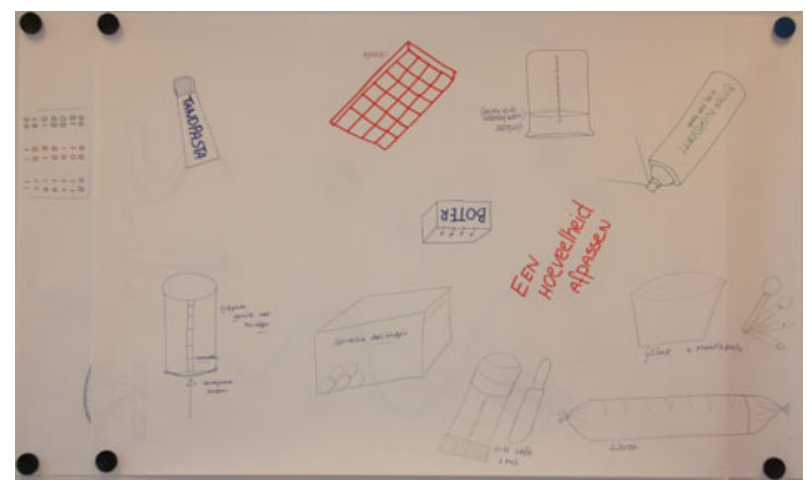

Fig. 12 Drawing possible solutions to a given task

In the third capability task in our proposed sequence we connect properties and tasks. Participants now have to look for combinations of physical properties and tasks. Here we can use the 'mysterious objects' activity that we described earlier. We have already mentioned that this exercise is a success. Participants of all ages are very interested in these strange objects. They are all eager to hold, touch or manipulate the things. Their interest in their neighbor's object is also well developed. However, each individual also has to fill his own worksheet and to mention as many properties and tasks as he can find. Groups only get a new object, when they hand in their completed worksheet. They get more than one object to describe. There is some overlap as some groups describe the same object as another group. After the groups have completed 2-3 objects they choose one object for the next task: to 'sell' the object to the group, the general public.

Each group gives a short presentation. These presentations also arouse more interest by the listeners than is customary with presentations in the classroom setting. Many of the objects are unfamiliar to the listeners and they all wonder what the quaint thing could be possibly be used for. Often objects are attributed functions that are fantastic, amusing, inspiring and sometimes unlikely to be thought of by the original producers. We expect that due to the experience of the previous two capability tasks, combined with a more structured instruction for the third task, teachers will be able to list more correct combinations of properties and tasks than we had observed in our exploratory study. We feel that this presentation stimulates the participants to select the main functional and physical properties to communicate about the artifact. In a 'sell' talk one is forced to focus on only the most relevant properties of the object that is to be sold and how these are realized effectively through certain physical properties of the artifact. Thus, the activity enhances an understanding of the nature of the artifact, and thus offers an entry for further reflection on technology and technological literacy.

We get a lot of feedback from the participants. Some of them contribute to our growing box of mysterious objects. Others want to borrow the box to use the activity in their own classroom. They report to us on the success and enthusiasm of their students, some of them even write about it in the teachers' journal. This shows that the mysterious objects activity is both motivating, but in combination with the other two proposed capability tasks can contribute to the teachers having a better understanding of the dual nature of technical artifacts. We see this small research study as the beginning of a larger research program in which we investigate more in-depth how teachers make links between functional and physical properties of artifacts. In that light the suggestions we have made above for 
improving artifact-related technology lessons is a preliminary proposal that we make with a certain caution, given the limitations of this study. We feel, however, that it has provided at least an indication that teachers do not 'naturally' get beyond only a very shallow and incomplete understanding of the nature of technical artifacts and that explicit interventions are needed to make them more acquainted with this nature. As stated before, we are convinced that learning about artifacts is an important contribution to technological literacy, not only because we mostly encounter technology through the artifacts that surround us, but also because their dual nature shows us both the human/cultural and the physical/ 'natural' side of technology, and the design process as bringing those two together. For that reason further research in teachers' understanding of the nature of technical artifacts can be a useful contribution to our field.

Open Access This article is distributed under the terms of the Creative Commons Attribution Noncommercial License which permits any noncommercial use, distribution, and reproduction in any medium, provided the original author(s) and source are credited.

\section{References}

Bame, E. A., Dugger, W. E., \& de Vries, M. J. (1993). Pupils' attitudes towards technology: PATT-USA. Journal of Technology Studies, 19(1), 40-48.

Dennett, D. C. (1989). The intentional stance. Cambridge, MA: MIT Press.

de Vries, M. J. (2005). Teaching about technology. An introduction to the philosophy of technology for nonphilosophers. Dordrecht: Springer.

Frederik, J. E., \& Sonneveld, W. (2007). Mysteries for sale. In M. J. de Vries, R. Custer, J. Dakers, \& G. E. Martin (Eds.), Analyzing best practices in technology education (pp. 83-92). Rotterdam/Taipei: Sense Publishers.

Kroes, P. A., \& Meijers, A. W. M. (2006). Introduction. The dual nature of technical artefacts. Studies in the History and Philosophy of Science, 37, 1-4.

Mitcham, C. (1984). Thinking through technology. Chicago: University of Chicago Press.

Vaesen, K. (2008). A philosophical essay on artifacts and norms (dissertation). Eindhoven: Eindhoven University of Technology. 